\title{
COMUNICACIÓN CORPORATIVA ON-LINE EN EL SECTOR MEDIOAMBIENTAL: SENSIBILIZACION Y PARTICIPACIÓN EN INTERNET
}

\author{
Ros Diego, Vicente \\ vros@uch.ceu.es \\ De Salas Nestares, $\mathrm{M}^{\mathrm{a}}$ Isabel \\ idesalas@uch.ceu.es \\ Departamento Comunicación Audiovisual, Publicidad y \\ Tecnología de la Información. Facultad de Humanidades y \\ Comunicación. Universidad CEU Cardenal Herrera.
}

Valencia.

Presentamos un ARTICULO. Material original autorizado para su primera publicación en la revista académica REDMARKA. Revista Digital de Marketing Aplicado.

https://doi.org/10.17979/redma.2009.01.02.4682

\section{Curriculum de Ros Diego, Vicente}

Doctor en Ciencias de la Información. Premio extraordinario de Doctorado en Comunicación. Máster M.B.A. y Licenciado en Publicidad y Relaciones Públicas por la Universidad CEU Cardenal Herrera.

Director de Comunicación Digital del CEU. Profesor de marketing y publicidad interactiva en la Universidad CEU Cardenal Herrera y en diversos posgrados. Además, es consultor docente de la Universitat Oberta de Catalunya.

Autor del libro "e-Branding. Posiciona tu marca en la Red". Investigador Principal de la Línea de Investigación "Comunicación, participación y sensibilización medioambiental en Internet". Miembro del Observatorio Beyond the line, del comité interactivo del Club de Marketing de Valencia, del Jurado del día de Internet de la Generalitat Valenciana, del Observatorio de Investigación en Medios Digitales y secretario de la Comisión de Nuevas Tecnologías del CEU.

REDMARKA UIMA-Universidad de A Coruña - CIECID

Año 1, Número 2, (2009), pp.3-35

http://www.redmarka.org/

ISSN 1852-2300 


\section{Curriculum de De Salas Nestares, $\mathrm{M}^{\mathrm{a}}$ Isabel}

Doctora en Ciencias de la Información por la Universidad Complutense de Madrid. Licenciada en Psicología por la Universidad Complutense de Madrid.

Ha sido Decana, Vicerrectora de Alumnos y actualmente Defensora Universitaria. Es Profesora agregada de la Universidad Cardenal Herrera-CEU, (Valencia). Profesora del Doctorado "Comunicación", Directora del Observatorio Beyond the Line. Vicepresidenta del Foro Iberoamericano de Estrategias de Comunicación FISEC, Profesora Honoraria de la Sociedad de Estudios Internacionales Madrid, Profesora del Master Universitario de Dirección y Gestión de Empresa de las Universidades de Alcalá de Henares y Complutense de Madrid. Miembro del Jurado de la Asociación de Autorregulación de la Comunicación Comercial -Autocontrol-. Miembro de la Junta de Gobierno del Colegio de Publicitarios de la Comunidad Valenciana. Ha publicado los libros: La comunicación empresarial en Internet. (2002) y La comunicación publicitaria interactiva en Internet (1999).

Resumen: El objeto principal del presente trabajo de investigación es la creación de un modelo de comunicación y sensibilización medioambiental en Internet. Un paradigma que proporcione los descriptores clave en la construcción de marca a través de Internet para el sector medioambiental, tanto para empresas con fines sociales "verdes", como para ONG's y Administración Pública. El objeto del modelo es la información, comunicación, participación y sensibilización del medioambiente entre los ciudadanos. La metodología de investigación del presente trabajo está basada en el análisis de contenido del corpus teórico de la comunicación y de Internet, así como un trabajo de investigación basado en un análisis de modelos de capital de marca y en un estudio del estado de las comunicaciones interactivas de tres organizaciones (agentes representantes del sector). Como puede comprobarse en el modelo, cada una de las estrategias de marketing y comunicación on line permiten potenciar los beneficios de Internet como medio con fines de: información, comunicación, participación, educación, sensibilización ciudadana.

Palabras clave: Branding, publicidad, Internet, web 2.0, blogs, publicidad, comunicación, marcas, usuario, interacción, eBranding, publicidad 2.0, 
marketing, marca, prosumer, crossumer, contenido, on demand, capital marca, sensibilización medioambiental.

Abstract: The main purpose of this research work is the creation of a model of communication and environmental awareness on the Internet. A Paradigm the descriptors that provide essential building brand via the Internet for the environmental sector, both for businesses with social purposes "green" as for NGOs and Public Administration. The purpose of the model is information, communication, participation and environmental awareness among citizens. The research methodology of this study is based on the content analysis of the theoretical corpus of communication and the Internet, as well as a research based on an analysis of models of brand equity and a study of the state of interactive communications Three organizations (agents sector representatives). As can be seen in the model, each of the marketing strategies and online communication allows enhance benefits of the Internet as a medium for information, communication, participation, education, public awareness.

Key Words: Branding, ad, Internet, Web 2.0, blogs, publicity, communication, marks, user, interaction, eBranding, publicity 2,0, marketing, mark, prosumer, crossumer, contained, on demand, brand capital, environmental awareness.

\section{Introducción}

La actual revolución de las Tecnologías de la Información y la Comunicación (TIC) esta cambiando totalmente la industria publicitaria. La etapa de una publicidad unidireccional, basada en el concepto de push (empujar el mensaje hacia el consumidor) UNO hacia MUCHOS y orientada a un público pasivo que forma la base de la publicidad da muestras de agotamiento. La comunicación en Internet es distinta; el anunciante debe emplear una estrategia pull, con la que atraer al consumidor hacia su mensaje. No se puede poner una página en la Red y esperar que alcance a su target. 
Paralelamente y gracias a esos avances en aplicaciones y herramientas de software la comunicación se decanta hacia MUCHOS a MUCHOS, rompiendo el paradigma clásico de la Teoría de la Comunicación (E-R-E)

Los datos actuales de audiencia e inversión publicitaria en Internet hacen necesario el replanteamiento de las estrategias de comunicación de las empresas, que deben orientar sus objetivos hacia un usuario cada vez más "hiperconectado". En esta era de la conectividad, en la que Internet se ha democratizado es necesario analizar la repercusión de la Red en la gestión de marcas de las organizaciones.

La sociedad del conocimiento actual ha generado cada vez mayor conectividad por parte del público objetivo al que se dirigen las comunicaciones corporativas en general.

Según el Estudio General de Medios en España se incrementa el número de usuarios conectados a Internet. En el siguiente gráfico podemos observar la evolución de usuarios españoles conectados a Internet. En 10 años se multiplica aproximadamente por un $\mathbf{1 . 8 0 0 \%}$ algo inédito en el mundo de las TeleComunicaciones (Fuente EGM Febrero Marzo 2008).

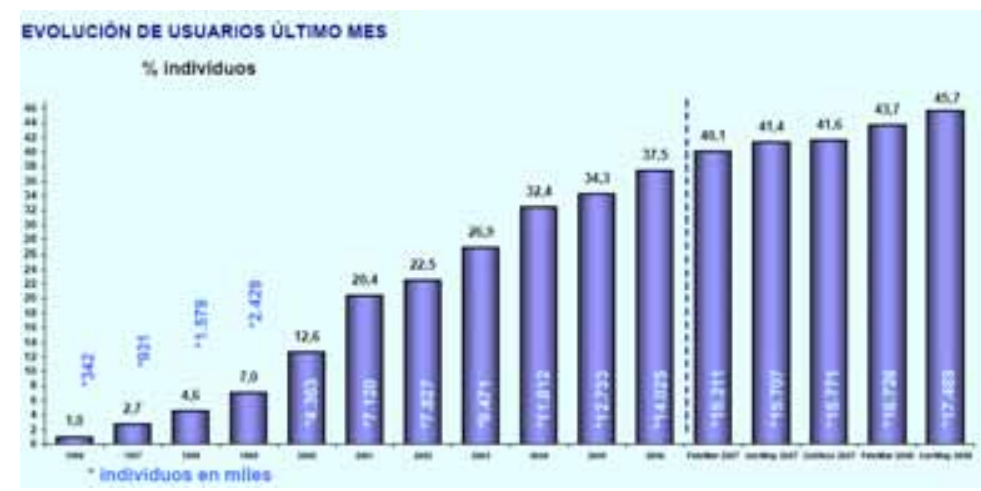

REDMARKA UIMA-Universidad de A Coruña - CIECID Año 1, Número 2, (2009), pp.3-35

http://www.redmarka.org/

ISSN 1852-2300 
Este crecimiento del uso de la tecnología en las comunicaciones corporativas, unido al crecimiento de audiencia de Internet, junto a la preocupación creciente por parte de empresas y gobiernos por la sensibilización medioambiental, hace necesaria una reflexión acerca de los modelos óptimos de comunicación que pueden desarrollar las organizaciones para informar, comunicar y hacer participar a los usuarios/clientes/ciudadanos de sus proyectos medioambientales.

No supone ningún descubrimiento la creciente importancia que ha asumido la protección del medioambiente en el contexto no solo de las comunicaciones, sino político, jurídico y social; sin embargo, pese a constituir una vexata questio, recién en las ultimas décadas la irrefutable realidad del cambio climático mundial, sumada a la creciente proliferación de terremotos, inundaciones, huracanes, maremotos, tsunamis, inviernos muy crudos, veranos extremadamente calurosos, etc. ha conminado a los gobiernos $y$ organizaciones a otorgar un lugar de primer orden en sus comunicaciones a dicha cuestión.

En este contexto, se considera vital desarrollar estrategias de comunicación al ciudadano que además de emplear medios como televisión, radio y prensa, usen Internet como fuente de información y concienciación.

A nivel general, las denominadas Estrategias $360^{\circ} 0$ campañas integrales contemplan Internet como medio complementario del resto de soportes, y al revés: campañas para Internet que se acompañan de mensajes en medios convencionales, lo que se refleja en la inversión publicitaria en medios, pues podemos contemplar que, en el primer cuatrimestre del 2008, el único medio que ha crecido en inversión publicitaria es Internet, junto a los canales temáticos (Fuente: Enero Junio 2008 Infoadex) 


\begin{tabular}{|l|l||l|l|}
\hline- & Enero-Junio 2008 & Enero-Junio 2007 & - \\
\hline \hline MEDIOS & millones de euros & millones de euros & $\%$ inc \\
\hline \hline TELEVISIÓN & $1.705,9$ & $1.778,8$ & $-4,1$ \\
\hline \hline DIARIOS & 805,8 & 961,3 & $-16,2$ \\
\hline \hline REVISTAS & 352,7 & 369,4 & $-4,5$ \\
\hline \hline RADIO & 343,5 & 355,2 & $-3,3$ \\
\hline \hline EXTERIOR & 231,1 & 238,5 & $-3,1$ \\
\hline \hline INTERNET & 110,6 & 86,2 & 28,3 \\
\hline \hline DOMINICALES & 53,1 & 62,0 & $-14,3$ \\
\hline \hline CANALES TEMÁTICOS & 30,9 & 27,6 & 12,1 \\
\hline \hline CINE & 11,1 & 19,5 & $-43,0$ \\
\hline \hline TOTAL & $3.644,7$ & $3.898,5$ & $-6,5$ \\
\hline
\end{tabular}

Este nuevo crecimiento cuantitativo del uso de Internet, debe ir acompañado de estrategias de comunicación de calidad que permitan la concienciación del ciudadano.

Dicha necesidad de calidad de impacto es más necesaria todavía en el contexto actual de sobresaturación. Por tanto, es necesario mejorar la relación con el cliente. Una relación que en Internet no se inicia en el propio web site de la marca sino en cualquier punto de la Red. Esto hace que técnicas de captación on line como: search marketing, blog marketing, marketing de afiliación, etc. deban gestionarse adecuadamente. Técnicas que deben ir acompañadas de acciones de concienciación para organizaciones cuyo objeto sea la influencia del ciudadano. Acciones como la óptima estructura de navegación, servicios con valor añadido y una participación del usuario basada en estrategias 2.0 (presencia en redes sociales, YouTube, etc.)

La multidireccionalidad y la funcionalidad accesible es lo que permite a la web2.0, que empezó a funcionar en el año 2004, romper con las web estáticas y obtener el mérito de pasar a la historia como pionera de un fenómeno social que sin duda supone un paso más hacia la generación NET.

REDMARKA UIMA-Universidad de A Coruña - CIECID 
Los nuevos servicios propios de la web 2.0 se constituyen en herramientas de participación y sensibilización medioambiental, que empiezan a ser gestionadas por diferentes organismos con dichos fines ${ }^{1}$.

\section{Objetivo}

La marca desempeña un rol estratégico en las organizaciones: esta afirmación produce consenso entre los responsables de la gestión de las empresas en cualquier parte del mundo. Según el Informe anual sobre el Estado de la Publicidad y el Corporate del año 2001 la gestión de marca no es sólo tarea del ámbito de comunicación, sino de todas las áreas de la organización.

"La creación de marca estaría centrada en conseguir establecer y mantener a lo largo del tiempo la mayor coherencia posible entre las expectativas creadas por la comunicación y la experiencia real de todos los públicos objetivos cuando entran en contacto con la marca" (Alloza, 2001: 210).

Los aspectos más importantes para la construcción efectiva de una marca son por orden de importancia y según el Informe anual sobre el Estado de la Publicidad y el Corporate:

1. Satisfacción de los clientes con el producto

2. Credibilidad y reputación de la organización

3. Calidad estratégica de comunicación

4. Volumen de inversión en comunicación

5. Desarrollo de valores de tipo emocional

Si se extrapolan los aspectos más importantes para la construcción efectiva de una marca al medio Internet, puede afirmarse que la satisfacción del usuario con el entorno digital, así como la reputación que el medio Internet logra gracias a la integración del usuario con la organización, se REDMARKA UIMA-Universidad de A Coruña - CIECID 9 Año 1, Número 2, (2009), pp.3-35 http://www.redmarka.org/ ISSN 1852-2300 
convierten en los dos factores más importantes para el gestor en comunicación institucional en Internet.

Cuando se habla de medioambiente se está transmitiendo una serie de conceptos y valores, al igual que cuando se habla de la marca BMW o Coca Cola. Es decir ¿Podríamos considerar el "Medioambiente" como una marca que necesita generar relaciones positivas y sinérgicas con el target humanidad?

¿Se podría crear un modelo de actuación estratégico en Internet que permita a todos los agentes del sector medioambiental actuar para crear actitudes correctas?

Si existe ya un modelo para la gestión de la marca (sea esta una institución o un producto/servicio) ¿Podríamos trabajar en los caminos que funcionan en Internet aplicándolo a la marca "medioambiente"? ¿Cómo generar la satisfacción (sentirse participe de una labor medioambiental) y la reputación (imagen de marca) deseada por dichos agentes?

El objeto de la presente investigación será, pues, la creación del modelo de capital de marca en Internet para el sector medioambiental, cuyo objeto es la información, comunicación, participación y sensibilización del medioambiente entre los ciudadanos.

\section{Metodología}

La metodología de investigación del presente trabajo está basada en el análisis de contenido del corpus teórico de la comunicación y de Internet, así como un trabajo de investigación que se expone en este apartado de manera resumida.

La presente investigación ha sido realizada en dos fases.

REDMARKA UIMA-Universidad de A Coruña - CIECID 
La primera fase consiste en analizar los diferentes modelos teóricos de la teoría de la usabilidad y gestión de marcas, definir y estudiar desde el punto de vista teórico los parámetros considerados clave en comunicación corporativa a través de Internet y finalmente en crear y revisar un modelo de dicha comunicación.

En la segunda etapa, y a partir del análisis documental, se desarrolla la investigación empírica, que básicamente se constituye en dos fases: generación de técnicas de evaluación de sitios web y análisis benchmarking de organizaciones con fines de sensibilización medioambiental. En concreto, se han seleccionado para el análisis la Administración Pública Valenciana Generalitat Valenciana-, una ONG (Greenpace) y una empresa privada con fines de sensibilización medioambiental (Iberdrola). La selección se ha basado en el criterio de que marketing social por Internet no lo desarrollan no sólo las empresas privadas, sino también organizaciones no gubernamentales y administración pública, aspecto que ya definió Kotler en 1969. En los tres casos son específicas sus campañas de comunicación asociadas al Medioambiente.

\section{Marketing social "verde" a través de Internet}

Hasta que Kotler y Levy² propusieron la ampliación del concepto de marketing, éste sólo se aplicaba al ámbito lucrativo. Estos autores recomendaron su aplicación a todo tipo de entidades que realizaran intercambios, independientemente del tipo de objetivos que les indujeran a actuar. Consideraban, no obstante, que si bien los principios generales eran los mismos, los principios ejecutores podían variar debido a las características propias de los distingos tipos de organizaciones, y en particular, de las ofertas y de los públicos de las organizaciones no lucrativas. Para opinar así, se basan en que el marketing se fundamenta en la idea general del intercambio y no únicamente en las transacciones de mercado. Así, siempre que se den ciertas 
condiciones, los intercambios pueden encontrar en el marketing un instrumento que los facilite ${ }^{3}$.

La ampliación del concepto genérico de marketing propuesto por Kotler y Levy tiene por tanto, una gran importancia puesto que, además de las empresas, hay un considerable número de organizaciones no empresariales que realizan múltiples intercambios en la sociedad. Es indudable que dichos intercambios se pueden ver favorecidos por los principios de marketing. Estas organizaciones tienen que satisfacer a su target y esto lo podrán hacer mejor si aplican los principios generales de marketing. Por ello, todas las organizaciones deberán emplear el marketing, y la cuestión estriba únicamente en si lo hacen bien o mal.

Siguiendo con el concepto de marketing aplicado a las organizaciones no lucrativas y administración pública, hay cierta confusión sobre el mismo pues, aunque hay quienes identifican el marketing no lucrativo con el marketing social, dicha identificación no parece adecuada porque la definición de marketing social abarca sólo las ideas o causas sociales. Sin embargo, dentro del sector no lucrativo, además de organizaciones que intentan transmitir, difundir y abogar por unas determinadas ideas o causas, sociales, hay otras que intentan trasmitir ideologías políticas (partidos políticos) o promover servicios de carácter público desde la administración (sanidad) y desde instituciones privadas (como los hospitales privados sin fin lucrativo). Ninguna de estas tres entidades tienen ánimo de lucro pero, sin embrago, el "producto" que tratan de difundir es distinto, y en ninguno de los casos, una causa social, por lo que requiere un nombre distinto.

Por tanto, en este artículo analizaremos las herramientas on-line que poseen diferentes organizaciones para mejorar su branding y marketing social.

El branding como proceso de creación de valor de marca (brand equity) debe convertirse en el eje en la administración estratégica del conjunto total de activos y pasivos vinculados al nombre y/o símbolo (isotipo) que identifican a la 
marca influyendo en el valor suministrado. En definitiva, el branding trata de construir no sólo identidad, sino también una entidad propia de marca, dotando a los productos del poder de una marca ${ }^{4}$.

Toda gestión de marca debe seguir un proceso basado en lo tangible y que evolucione hacia lo intangible. Young \& Rubicam ha plasmado esa evolución en un proceso de brand laddering, en cuatro fases:

- Espacio mental: qué se es en la mente del consumidor, basado en la USP (Unique Selling Proposition)

- Tangibilización: los beneficios funcionales hacen distinta a la marca.

- Vínculo emocional: qué siente el consumidor por la marca, basado en beneficios emocionales que aportan personalidad propia.

- Brand comunity: qué se es si se está con la marca, basado en unos valores que configurarán la esencia de marca.

Gestionar eBranding debe ir más allá de tener presencia en la Red con un logo más o menos adaptado a una interfaz digital. El look and feel o aspecto gráfico de un site es muy importante, pero sólo es un ingrediente.

Según G. Vallet ${ }^{5}$

"eBranding es, sobre todo, la experiencia del usuario, es cada aspecto de la relación entre la compañía y el usuario en la Red. Los logos y los tagline (eslogan en Internet) son efectivos sólo si suman la actitud de una empresa. Soportan la marca, pero no la crean. El eBranding culmina en un símbolo que la gente asocia con él, con una experiencia que tienen con la organización, pero el trabajo duro del eBranding está en crear dicha experiencia. El eBranding es el proceso de transformar un sitio web en una experiencia única para el usuario. Única por la calidad de su diseño, por la utilidad y usabilidad de sus contenidos y por la 
simple y eficaz lógica funcional en la navegación e interacción con dicho sitio web"

Todo objetivo de comunicación mix debe perseguir, por una parte, la máxima atracción a la web y, por otra, la posterior fidelización. De hecho, resulta más interesante retener que captar en la Red, ya que según la mayoría de estudios, un 75 por ciento de usuarios deja el proceso de compra tras haber llegado al sitio. Según J. Alet, las técnicas de captación on line deben usarse empleando un mix estratégico. Algunas de estas técnicas son (Alet, J.: 2007):

- Gestión del nombre del dominio

- Posicionamiento natural y publicitario en buscadores

- Vínculos con otros sitios

- Campañas de comunicación off line

- Conferencias y relaciones con prensa digital y websites

- Campañas on line: banners, e-mail, notas prensa, links, patrocinios

- Programas de afiliados

- E-mail marketing y marketing viral

- Optimización en redes sociales

- Presencia en blogs

Por otra parte, es necesario gestionar un plan de fidelización de la web. Las importantes sumas de dinero invertido en captación se pierden por no haber establecido señales comprensibles en la navegación, servicios básicos al usuario, garantía de velocidad de flujo y diseño visual atractivo.

La conversión de visitante en usuario (portal) o comprador (comercio electrónico) depende de factores como:

1. Usabilidad: facilidad de uso y navegación intuitiva.

2. Contenido valioso. Factores: detalle de información, actualidad y utilidad, exclusividad, entretenimiento, asesoramiento y comunidad.

3. Imagen atractiva.

REDMARKA UIMA-Universidad de A Coruña - CIECID 


\section{Personalización. \\ 5. Comunidad de marca.}

La gestión del eBranding, por último, conlleva analizar al usuario, estudiar las opiniones de los consumidores y reflexionar sobre los comentarios de los receptores. Destinatarios que abandonan su rol de simple "receptor" para convertirse en emisores de la propia marca de la empresa gracias a la tecnología en Internet y a los nuevos servicios de la web 2.0.

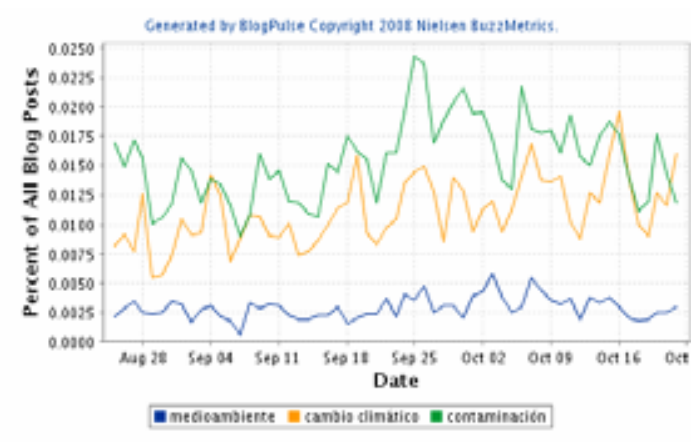

Para analizar los mensajes que depositan los usuarios en chats, listas de correo, grupos de noticias o blogs existen varias herramientas en el mercado. Una de estas herramientas es Blog Pulse de Nielsen (www.blogpulse.com), que mide gráficamente cuántos comentarios se realizan sobre una marca y los compara con lo que se dice de la competencia.

Esta herramienta podemos aplicarla al estudio de la influencia e interés de los navegantes en relación a temas medioambientales. Así, si en octubre de 2008 realizamos un análisis de interés por los conceptos "contaminación" "medioambiente" y "cambio climático", observamos una tendencia clara de la población hacia la sensibilización por la lucha del cambio climático en la blogosfera:

\section{Análisis del estado de la comunicación de marketing social "verde" on-line de tres organizaciones}


Como se ha comentado, en el presente trabajo de campo se ha analizado una ONG (Greenpace), una empresa con fines de marketing medioambiental (Iberdrola) y una administración pública (Generalitat Valenciana)

\section{Greenpace}

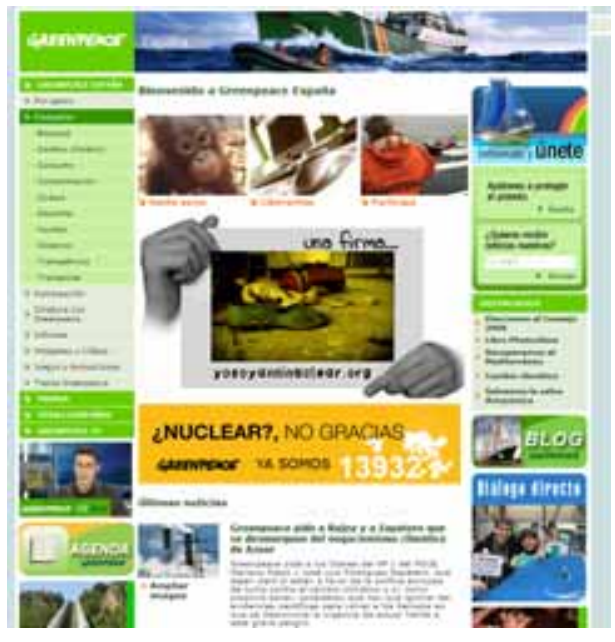

Greenpeace se implantó en España en 1984. La organización contaba entonces con más de un millón de socios en todo el mundo y oficinas en doce países. Aunque el perfil de socio mayoritario de Greenpeace pertenece a la generación Net tardía (inmigrantes digitales de 30 a 45 años), el núcleo de sus simpatizantes on line son jóvenes de todo el mundo familiarizados consciente 0

inconscientemente con la nueva era de Internet. Jóvenes (nativos digitales) de distintas ideologías y procedencias pero con una preocupación común: la salud de un planeta cada vez más dañado por la actividad humana.

Greenpeace desarrolla notas de prensa para medios on-line, un diseño muy cuidado de newsletters y herramientas 2.0. Por otro lado, la sala de prensa on line se limita a un listado de notas de prensa, con el aliciente, sin embargo, de que permiten al interesado que comuniquen su necesidad de cualquier otro tipo de información, vídeo, archivo o material. 

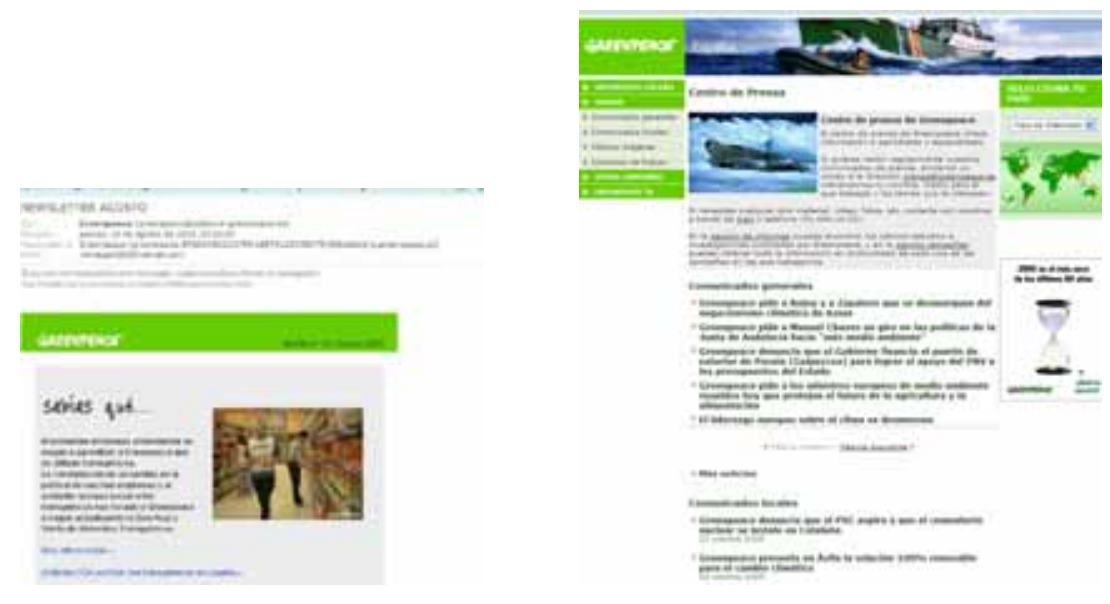

Actualmente hay sólo un responsable profesional dedicado a los contenidos del Blog corporativo, que cuenta con el apoyo y participación del todo el equipo. Este Blog es contenedor principalmente de artículos de opinión y de las acciones en vivo llevadas por la empresa. Como ejemplo el caso ENDESA, donde el Blog sirvió para denunciar en directo y al mismo tiempo que se realizaba la protesta en la sede de ENDESA físicamente.

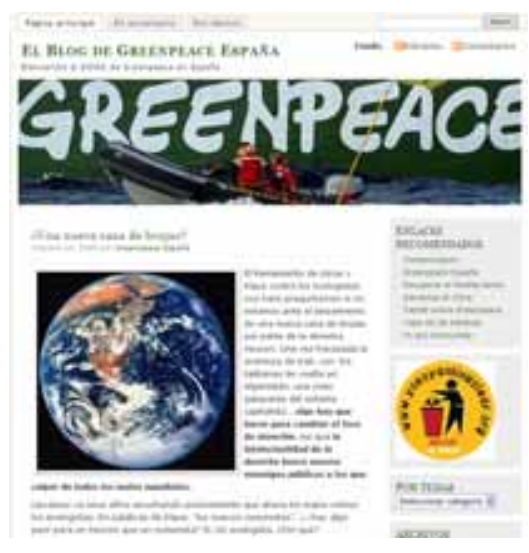

Para analizar Greenpace, con el su competencia directa, se ha empleado la herramienta de Nielsen "BlogPulse". El gráfico nos muestra que, aunque Greenpeace se beneficia de una superioridad en todos los meses

REDMARKA UIMA-Universidad de A Coruña - CIECID

Año 1, Número 2, (2009), pp.3-35

http://www.redmarka.org/

ISSN 1852-2300 
exceptuando marzo, la tendencia marca ventaja cada vez inferior con respecto a WWF-Adena. Aunque nuestro objetivo no es medir el conocimiento de marca en comparación con WWWF-Adena, éste sí es un indicador relativo del conocimiento líder de Greenpeace frente al que esta compañía considera su competidor directo. Este resultado puede deberse a que por ejemplo WWFAdena no dispone todavía de un Blog corporativo.

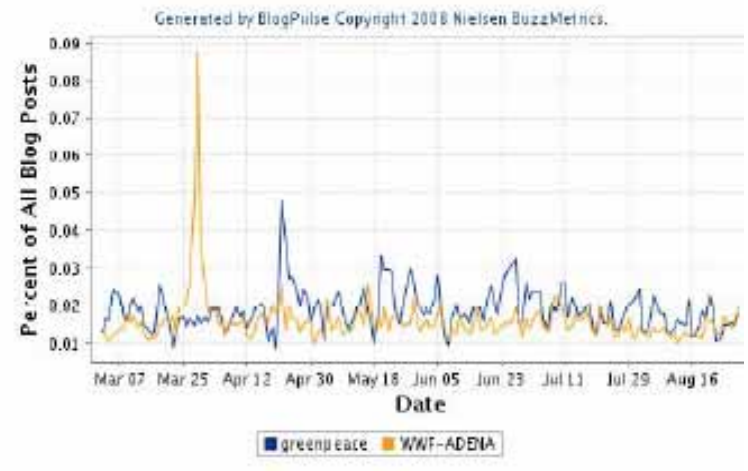

La estrategia on line llevada a cabo por Greenpeace, sigue la siguiente filosofía: se destinan más o menos recursos según objetivos y, a su vez, estos objetivos dependen de la medición del pulso del interés de los usuarios. Es decir, si por ejemplo es percibido por la organización que, existe un mayor interés en determinado período por "la construcción ilegal en las costas de x ciudad o país" se desarrollará con prioridad una web ad hoc contenedora de información y material afín elaborado por fuentes propias antes que un microsite o un espacio en el Blog por la idoneidad de la naturaleza de ambos formatos comparado con la web. Siguiendo con este ejemplo, el hecho de que hubiera un alto índice de interés en los buscadores por el tema de la construcción ilegal, propició la creación de la web denominada “construcciónatodacosta”.

El caso más reciente lo protagoniza ENDESA con la campaña "para los hijos de tus hijos". Desde que Greenpeace consideró esta campaña como "publicidad engañosa" o "engaño verde", e invirtió todos los recursos que están a su alcance para lanzar este mensaje al mundo,

REDMARKA UIMA-Universidad de A Coruña - CIECID

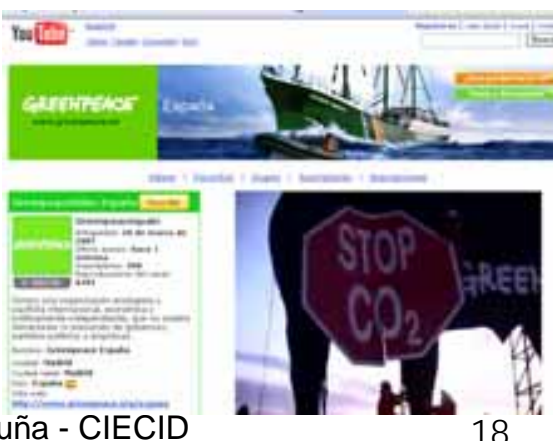
Año 1, Número 2, (2009), pp.3-35 http://www.redmarka.org/ ISSN 1852-2300 
son muchos los usuarios que se han interesado por tal concepto, muchas noticias que relacionan a Greenpeace con tal concepto y cuya fuente no es la organización y muchos los usuarios que han demostrado interés por la contrapublicidad de Endesa creada por Greenpeace - que ya cuenta con más de 35.000 visualizaciones del vídeo colgado por la organización- en YouTube-

Como conclusión podemos afirmar que las ONGs no quedan excluidas de practicar políticas de marketing similares a las de otras compañías lucrativas. En concreto, Greenpeace también hace suyas las políticas de marketing mix de comunicación on line y las herramientas 2.0 para generar branding.

Greenpeace, en la actualidad, se consolida como ONG medioambiental internacional líder. El conocimiento de marca a través de las herramientas 2.0 es elevado y superior al de su competencia directa, WWF-Adena. Sin embargo, la monitorización de la blogosfera muestra una tendencia en la se reduce la diferencia entre ambas organizaciones.

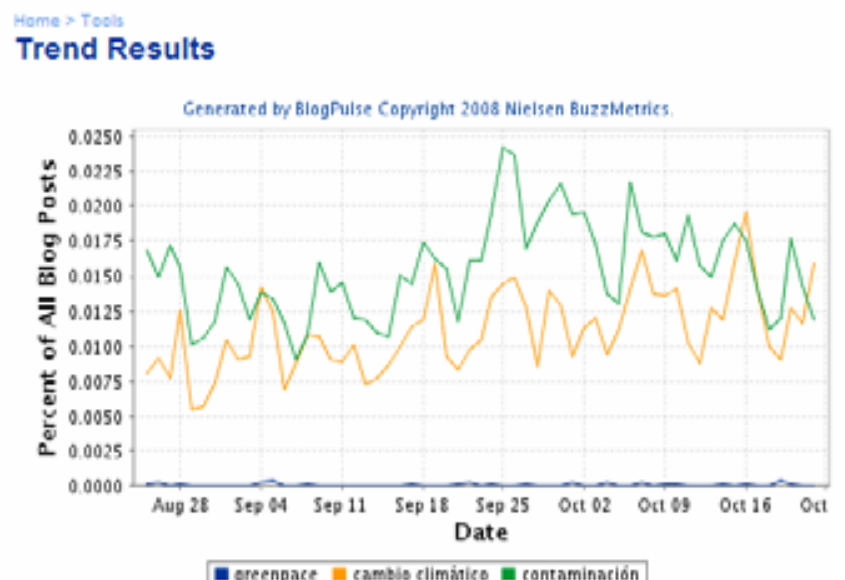

El ciberactivismo emerge con una gran fuerza. El uso adecuado del marketing viral y otras herramientas 2.0 que permitan colaborar con Greenpeace de una forma inmediata...serán necesarias para conseguir uno de los parámetros clave de Greenpeace: la colaboración y la captación de socios. Por lo tanto, aunque hay una confianza en que la tendencia futura situará a la 
web 2.0 como la forma más adecuada y directa para relacionarse con la organización, todavía no se considera suficientemente adecuada para favorecer su relación con la misma.

\section{Generalitat Valenciana}

El Gobierno Autonómico realizó desde el 2 de mayo de 2008 una campaña en televisión de concienciación medioambiental

Cambia para que no Cambie

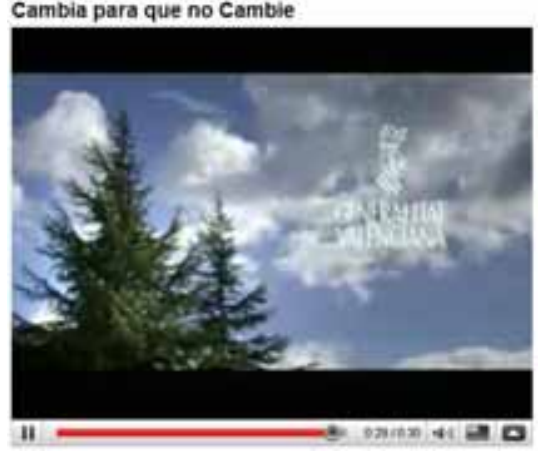

invitando a visitar la dirección

www.cambiaparaquenocambie.com

El objetivo era, sin duda, provocar una concienciación entre la ciudadanía sobre el cuidado del Medioambiente haciendo hincapié en la labor y la responsabilidad individual.

Hubo diferentes spots mostrándose un gran interés por parte de los poderes públicos sobre este tema.

La página se inicia con una invitación a dar los datos del usuario (nombre y email) para plantar un árbol con su nombre. Sin duda es una acción interesante para recoger direcciones de email y para dar cierta interactividad a la página, pero sobretodo propone la implicación del usuario TU PUEDES FRENAR EL CAMBIO CLIMATICO.

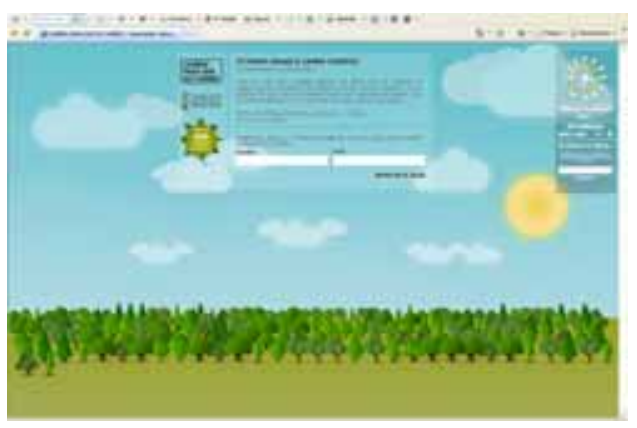

El diseño resulta sencillo, quizás demasiado infantil (te invitan a descargarte unos emoticones). Se puede visionar todos los spots y el acto de presentación de la campaña por el 
Vicepresidente D. Vicente Rambla.

La estructura es muy simple y en castellano: Un menú de 5 epígrafes:

Novedades, Nuestros consejos (Aven, enlace a Agencia Valenciana de la Energia y CLARITY, enlace a acción educativa por el clima), Vuestros consejos (comentarios de usuarios), Especies de árboles (de la Comunidad Valenciana) Enlaces de interés.

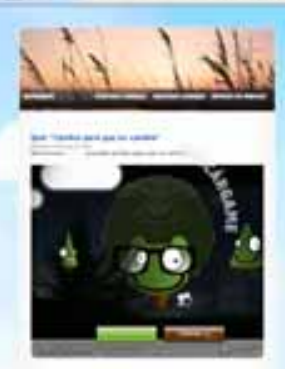

árboles y luego una lista de nombres científicos y su traducción vulgar pero no te enlazan a fotos del árbol e información de cuanto viven, que características tienen, cómo plantarlo o cuidarlo. El contenido es escaso.

b) Tiene un marcado carácter didáctico dirigido a un público infantil y juvenil

En los enlaces de interés se informa: "Desde esta sección podrás acceder a todos aquellos portales Web que la Generalitat Valenciana considere interesantes dentro de la lucha por la conservación del medio ambiente". Sin embargo sólo dan 4 enlaces: Generalitat Valenciana, Conselleria de Medio Ambiente, AVEN Agencia Valenciana de la Energía y Campus Party.

La interactividad la realizan con la sección de "Vuestros consejos". Invita a que el usuario aporte sus comentarios para cuidar el medio ambiente.

Las Novedades tienen fecha de hace cuatro meses. Es decir no hay una actualización de temas. Esto es clave para volver a visitar la web.

REDMARKA UIMA-Universidad de A Coruña - CIECID

http://www.redmarka.org/

$$
\text { ISSN 1852-2300 }
$$


A nivel de usabilidad se detectan muchos enlaces no activos.

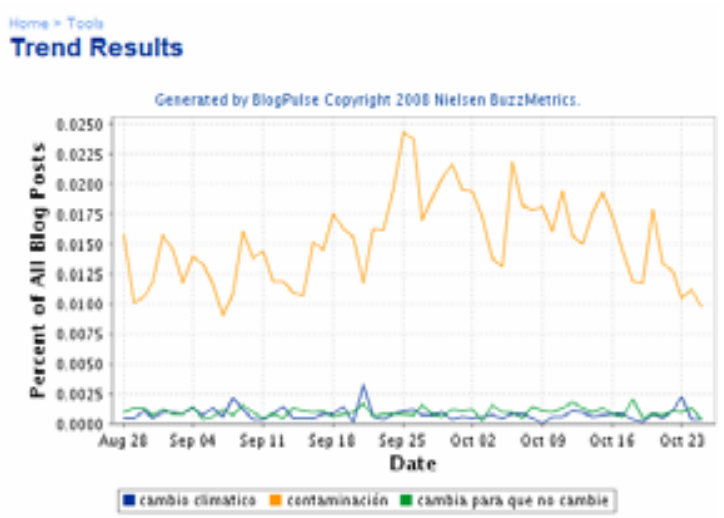

\section{Iberdrola}

Con más de 100 años de experiencia, IBERDROLA es una de las PRINCIPALES COMPAÑÍAS ENERGÉTICAS del mundo y está presente en 30 países. Mantiene su compromiso histórico de apoyo a las comunidades en las que opera, haciendo compatible el cumplimiento de su misión empresarial con el respeto por el medio ambiente y la contribución al progreso de la sociedad.

Iberdrola realiza una un comunicación institucional basada en herramientas como revistas, boletines, publicidad, etc. En concreto:

Energía Interna

Portal del Empleado

Ibernoticias Digital//bernoticias Latinoamérica

Boletines digitales

Buzón del Empleado

Concurso tarjetas de Navidad

Comunicación para directivos

Comunicados radiofónicos

Cartas del Presidente

REDMARKA UIMA-Universidad de A Coruña - CIECID http://www.redmarka.org/ ISSN 1852-2300 


\section{Portal del Empleado}

Banners, posters, folletos, tablones...

La comunicación on-line de Iberdrola destaca por su capacidad para generar

branding mediante el uso de herramientas interactivas por la Red como:

\section{WEB CORPORATIVA}

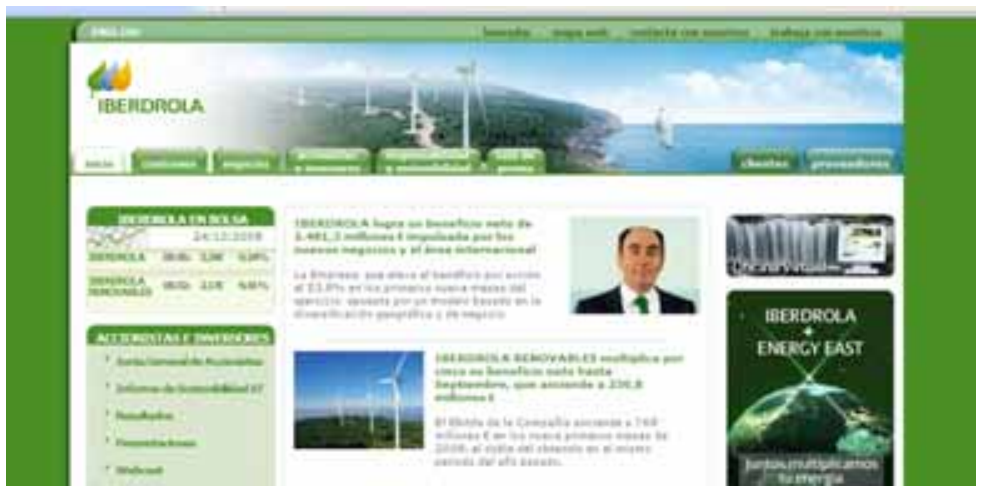

\section{PORTAL DEL EMPLEADO}

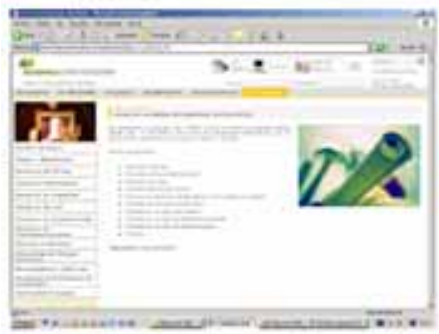

Todos los empleados disponen de acceso al Portal del Empleado.

- Potente herramienta que activa la comunicación interna

- Aporta identidad corporativa

- Facilita el trabajo

- Crea vinculos de unión entre los empleados de la Compan̂ia.

\section{IBERNOTICIAS DIGITAL}

- Periódico digital actualizado permanentemente.

- Responde a la demanda creciente de información por parte de los empleados.

- Constituye su principal fuente de información.

- La transparencia informativa nige a la hora de seleccionar las noticias a publicar.

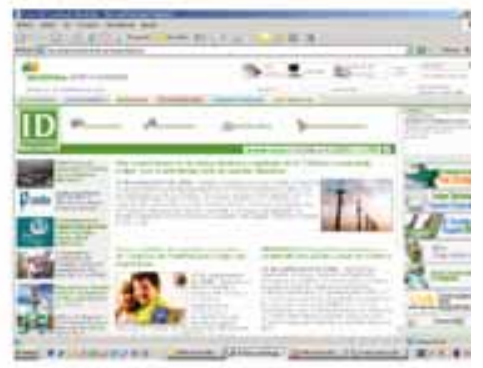

REDMARKA UIMA-Universidad de A Coruña - CIECID

Año 1, Número 2, (2009), pp.3-35

http://www.redmarka.org/

ISSN 1852-2300 


\section{BOLETINES DIGITALES \\ Persiguen sensibilizar a los empleados sobre un tema especifico que asi lo requiera \\ - Cuentan con un formato atractivo. flexible y sencillo \\ - Se envia por correo electrónico a toda la plantilla.

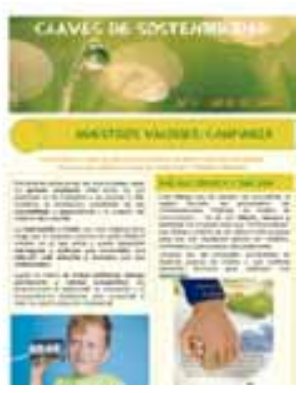

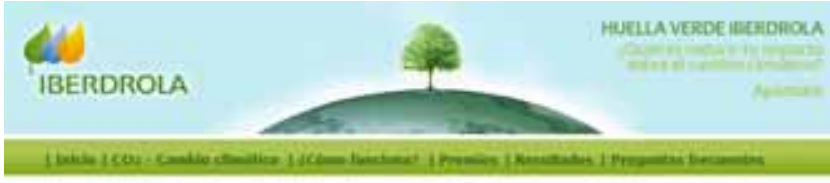

Microsites que informan y sensibilizan sobre aspectos

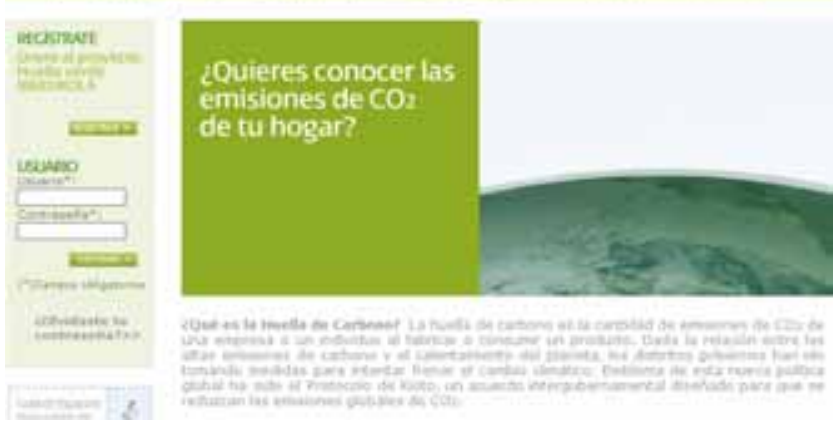
medioambientales
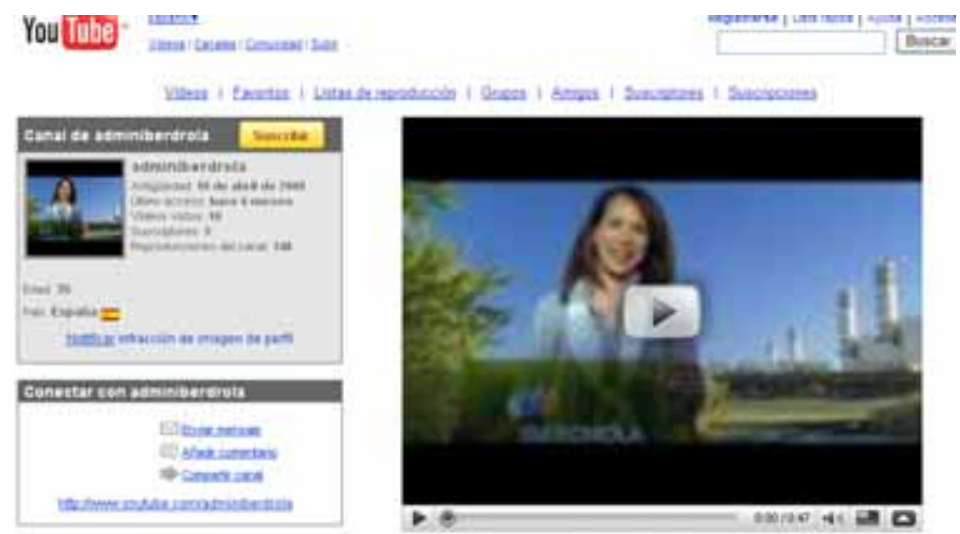

Canal en YouTube con vídeos sobre sus campañas:

En relación a políticas de comunicación destaca la campaña que Iberdrola Renovables desarrolló por la Red. Las imágenes del spot cuidan mucho los detalles y el medio ambiente pasa a ser la parte principal de los

REDMARKA UIMA-Universidad de A Coruña - CIECID

Año 1, Número 2, (2009), pp.3-35

http://www.redmarka.org/

ISSN 1852-2300 
valores que esta empresa pretende mostrar. Para la música se ha escogido la canción de Los Beattles Mother Nature's son (Hijo de la Madre Naturaleza).

Además de la web corporativa, microsites, canal YouTube y campañas publicitarias on line, destaca su implicación en documentales ${ }^{6}$ que pasan a convertirse en referente para que en Internet la compañía se perciba como una organización que fomenta la sensibilización medioambiental.

\section{Modelo de comunicación corporativo medioambiental en Internet}

El capital de marca es el valor añadido con el que se dota a productos y servicios. Como afirma Kotler, este valor se puede reflejar en cómo piensan, sienten y actúan los consumidores respecto a la marca, o en los precios, la cuota de mercado y la rentabilidad que genera la marca para la empresa. En cualquier caso, el capital de marca es un activo intangible basado en la percepción de marca del consumidor.

Este capital de marca configura el capital cliente de una empresa. Según Kotler, el capital cliente suma todos los valores de vida de los clientes de una empresa. Es el sumatorio de:

a) Capital valor: valoración objetiva que hace el cliente en función de calidad, conveniencia, etc. En Internet, podría ser la calidad informativa de una web.

b) Capital marca: valoración subjetiva en función de la notoriedad de marca, la actitud hacia la misma y la percepción ética de todos los soportes on line y off line.

c) Capital relaciones: tendencia de los consumidores a ser leales (programas de fidelidad, programas de reconocimiento y tratamiento especial, creación de comunidades virtuales, etc.)

REDMARKA UIMA-Universidad de A Coruña - CIECID 
Tal y como se ha expuesto en el análisis del estado de comunicación online de las tres organizaciones del apartado anterior, cada una de las herramientas que nos ofrece Internet, mejoran el capital de marca, al crear valor y generar relaciones interactivas entre todos los miembros, en este caso, preocupados por temas medioambientales.

Los cuatro modelos de gestión de capital de marca más consolidados son $^{7}$ :

\section{a) Brand Asset Valuator}

Desarrollado por Young \& Rubicam. Según el modelo, existen cuatro componentes clave del capital de marca: diferenciación (grado en el que una marca es diferente al resto), relevancia (atractivo de una marca), estima (reputación y satisfacción de las promesas percibidas por el consumidor) y conocimiento (nivel de familiaridad e intimidad de los consumidores con la marca).

Figura Modelo Brand Asset Valuator

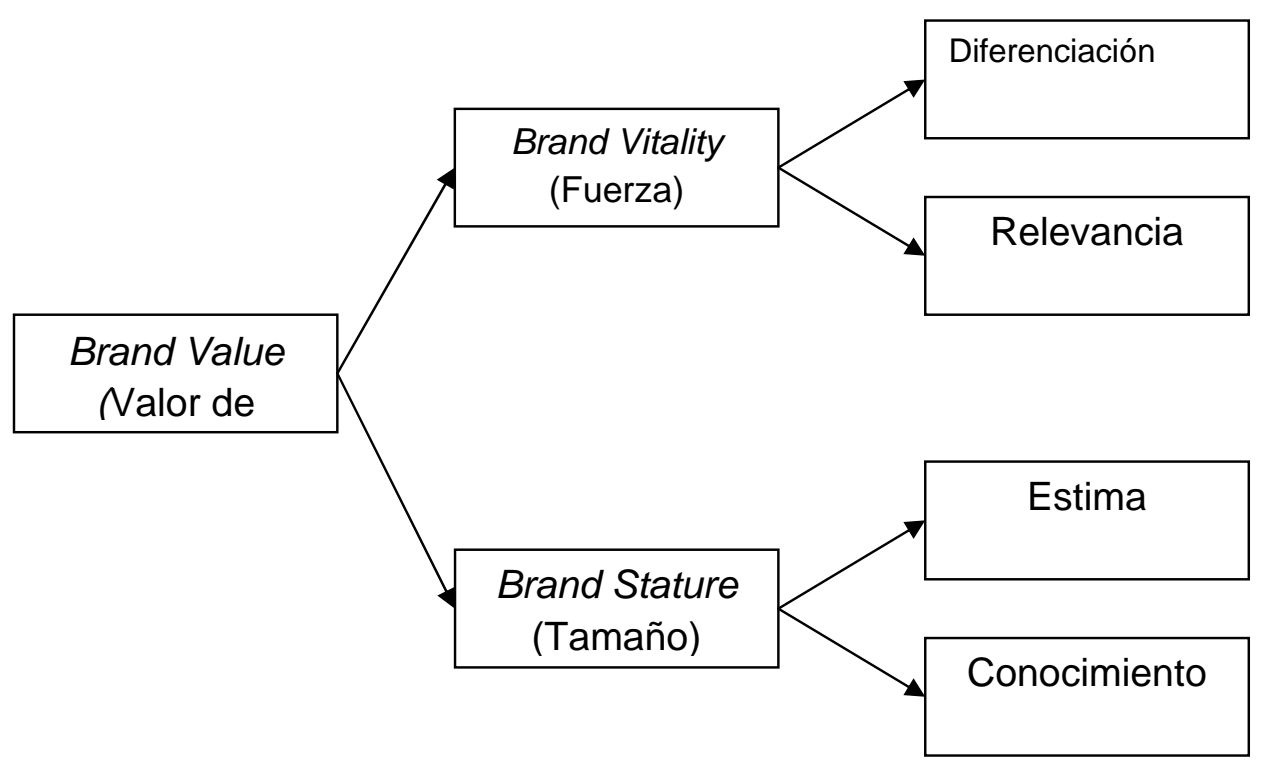

Diferenciación $\times$ Relevancia $=$ Fuerza de marca

REDMARKA UIMA-Universidad de A Coruña - CIECID

Año 1, Número 2, (2009), pp.3-35

http://www.redmarka.org/

$$
\text { ISSN 1852-2300 }
$$




\section{Estima $\times$ Conocimiento $=$ Tamaño de marca}

\section{b) Brand Z}

Desarrollado por Millward Brown y WPP. Gira en torno a la pirámide Brand Dynamics.

Enumera cinco niveles en una pirámide en función del grado de lealtad:

- Presencia (familiaridad activa en la prueba de la promesa: ¿Conozco la marca?)

- Relevancia (cubre necesidades en el rango de precios adecuados: ¿Me ofrece algo?)

- Funcionamiento (correcto funcionamiento del producto: ¿Qué me entrega?)

- Ventaja (basada en atributos emocionales, racionales o de notoriedad: ¿Me ofrece algo mejor que los demás?)

- Compromiso (vínculos racionales y emocionales: Nada puede superarla).

Figura . Modelo Brand Z

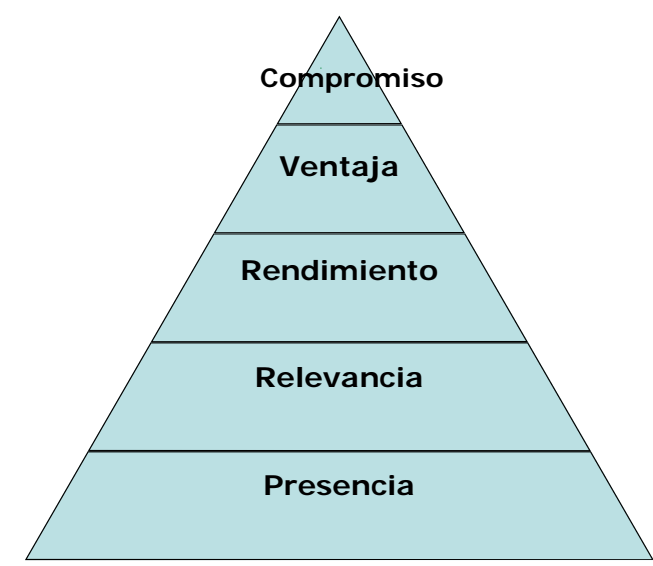

REDMARKA UIMA-Universidad de A Coruña - CIECID

Año 1, Número 2, (2009), pp.3-35

http://www.redmarka.org/

$$
\text { ISSN 1852-2300 }
$$


c) Modelo de Aaker

El capital de marca está formado por cinco categorías de activos y pasivos ligados a una marca: lealtad a la marca, notoriedad, calidad percibida, asociaciones de marca y otros activos propiedad de la marca (patentes, marcas registradas, etc.).

d) Modelo de Resonancia de la marca

Considera que la creación de marcas es un proceso ascendente:

1. Garantizar que los clientes identifiquen la marca.

2. Establecer la totalidad del significado de la marca en la mente del cliente.

3. Provocar respuestas apropiadas del cliente en cuanto a juicios y opiniones.

4. Transformar respuestas para crear una relación intensa y activa de lealtad.

Estas cuatro fases se pueden agrupar en seis bloques de construcción de marcas con el cliente a modo de pirámide. Este modelo hace hincapié en la dualidad de las marcas: la ruta racional (izquierda) y la emocional (derecha).

REDMARKA UIMA-Universidad de A Coruña - CIECID 
Figura . Modelo de resonancia de marca
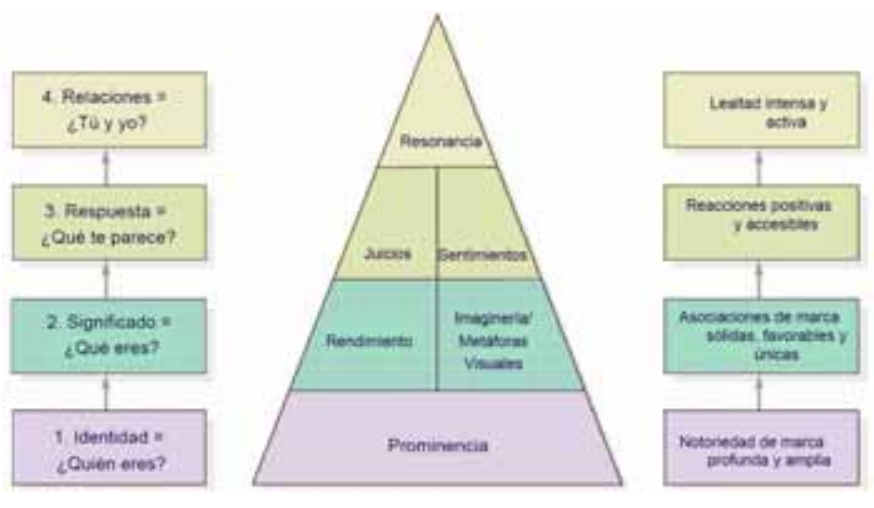

El estudio de la EIAA sobre la Eficacia del Branding Online concluye que la publicidad online consigue mejorar significativamente los resultados obtenidos en los cinco parámetros de medición del branding al completo (conocimiento del anuncio, conocimiento de marca, predisposición favorable a la marca, asociación de ideas e intención de compra).

Estos 5 parámetros, se pueden extrapolar al ámbito medioambiental. Y cada uno de ellos ser gestionados por diferentes herramientas en la Red.

El modelo que ahora se presenta se basa en los cuatro expuestos. Pretende describir cómo se desarrolla el capital de una marca en Internet, y por ende, recoge los parámetros básicos de la comunicación publicitaria en Internet cuyo objeto es la información y sensibilización medioambiental por parte de organizaciones que pretenden posicionarse en este sentido.

El modelo de comunicación medioambiental en Internet parte de la premisa que cada uno de los parámetros del branding puede desarrollarse con Internet mediante diferentes herramientas como canal propicio para la participación, educación y sensibilización ciudadana.

REDMARKA UIMA-Universidad de A Coruña - CIECID 
Para desarrollar el parámetro "recuerdo de anuncio" que lleva a proporcionar la información necesaria para sustentar una actitud positiva se requiere una estrategia de comunicación en Internet aplicado al desarrollo de un site específico, actualizado y de calidad.

Para acrecentar el parámetro de conocimiento de marca deberá invertirse en publicidad en otros medios y también en Internet a través de Portales, diarios digitales, buscadores, etc. Así como acciones de email marketing mediante newsletters.

Para fomentar la predisposición favorable se recomienda implicar al usuario invitándole a participar en foros, blogs y wikis.

La sensibilización pretendida se alcanzará mediante la utilización de los propios usuarios y sus contactos mediante la prescripción "viral".

Finalmente la intención de compra, en este caso, la conducta responsable con el medioambiente, puede inducirse mediante estrategias WOMM (Marketing boca-oreja) basadas en redes y anuncios sociales.

REDMARKA UIMA-Universidad de A Coruña - CIECID 


\begin{tabular}{|ccc|}
\hline $\begin{array}{c}\text { PARÁMETROS } \\
\text { BRANDING }\end{array}$ & $\begin{array}{c}\text { INFLUENCIA EN EL } \\
\text { CIUDADANO }\end{array}$ & $\begin{array}{c}\text { ESTRATEGIA DE } \\
\text { COMUNICACIÓN ON- } \\
\text { LINE }\end{array}$ \\
\hline $\begin{array}{c}\text { RECUERDO ANUNCIO } \\
\text { CONOCIMIENTO } \\
\text { MARCA }\end{array}$ & Comunicación & $\begin{array}{c}\text { Web / microsite } \\
\text { Publicidad en otras web } \\
\text { (portales, Adword...) }\end{array}$ \\
\hline $\begin{array}{c}\text { PREDISPOSICIÓN } \\
\text { FAVORABLE A LA } \\
\text { MARCA }\end{array}$ & Implicación & $\begin{array}{c}\text { Foro } \\
\text { blog }\end{array}$ \\
\hline $\begin{array}{c}\text { ASOCIACIÓN DE } \\
\text { IDEAS }\end{array}$ & Sensibilización & wikis \\
(marca - valores) & Concienciación & Prescripción \\
\hline INTENCIÓN DE & Participación & Social media \\
COMPRA & Conducta responsable & \\
\hline
\end{tabular}

\section{Conclusiones}

De este modo, cada una de las estrategias de marketing y comunicación on line nos permiten potenciar los beneficios de Internet como medio con fines de: información, comunicación, participación, educación, sensibilización ciudadana.

Las comunicaciones interactivas logran mediante determinadas herramientas como microsites o boletines, la sensibilización "puntual" del usuario. Este estado es insuficiente, y por ello los gestores de comunicación deben también gestionar las nuevas herramientas propias de la web 2.0 (blog, 
redes sociales, microblogging, wikis) cuyo objetivo van más allá de la sensibilización "puntual" al conseguir una sensibilización medioambiental "duradera". Se hace necesario por ende, desarrollar las nuevas herramientas 2.0 para generar un modelo de comunicación que genere un branding óptima para las marcas de este sector. Así, tras conseguir esta actitud, hay que hacer participar al usuario. La participación es el paso que se habrá conseguido cuando el usuario se identifique con la marca, cuando la haga suya, cuando haya detectado beneficios útiles, racionales, emocionales y sociales.

En este sentido, la propuesta va en la línea de la nueva definición de marketing difundida por la American Marketing Association: "Marketing es una función de las organizaciones y un conjunto de procesos orientados a crear, comunicar y aportar valor a los consumidores y para dirigir las relaciones con éstos de la manera más beneficiosa para la organización y para sus stakeholders (grupos de interés)".

En dicha definición destaca la función de las organizaciones como creadoras de valor y generadoras de relaciones. Ambos aspectos implican la necesaria gestión de reputación de marca, que es el objetivo final del presente modelo.

Nos encontramos por tanto en la era de la comunicación basada en la transparencia, donde el consumidor tiene más que nunca el poder sobre los medios y donde la voz del usuario pasa a ser la voz de la marca.

Es el "usuario 2.0", un consumidor de nueva generación, experto, que decodifica las intenciones de las campañas publicitarias y se revuelve contra el monólogo comunicativo de las grandes compañías. Es el crossumer (concepto creado por The Cocktail Analysis en 2007), un consumidor que ha cruzado la línea infranqueable que lo separaba del productor (cross significa cruzar), convirtiéndose en emisor real de mensajes, con un carácter de compromiso mayor con aquellas marcas que se comprometen con él y con sus amigos. En 
el caso del medioambiente se puede afirmar que la concienciación fluye por la red mostrando signos de un ciudadano más responsable e implicado con el entorno natural.

Como nos dice el Manifiesto Cluetrain:

"No hay secretos. Las compañías necesitan bajar de su pedestal y hablarle a la gente con quien esperan establecer relaciones. Pero primero, deben pertenecer a una comunidad. Si quieres que te dirijamos la palabra, dinos algo. Que sea algo interesante para variar.

Nuestra lealtad es para con nosotros mismos, nuestros amigos, nuestros nuevos aliados y conocidos, hasta nuestros compañeros de batalla. Las empresas que no juegan un papel en este mundo, tampoco tienen futuro"

\section{Notas al final del texto}

1. Así por ejemplo, Acción Natura desarrolló una campaña de marketing viral para concienciar al público joven de la importancia de su actitud frente al cambio climático, Greenpeace diseñó una plataforma de participación ciudadana en la Red, la Generalitat de Catalunya un canal en YouTube para comunicar la biodiversidad de sus costas, etc.

2. Kotler, P.; Levy, S.J. (1969): "Broadening the Concept of Marketing", Journal of Marketing, Vol. 33,. №1, Enero, Pp. 10-15

3. ALDAMIZ-ECHEVARRÍA, C. (2003). Marketing en ONGs de desarrollo. 16 ed., Madrid. Página 41.

4. Kotler, P. et al, Dirección de marketing, Pearson, 2006.

5. eBranding. La creación de marca digital en la era de la conectividad. Autores: Gemma Vallet Saavedra; Directores de la Tesis: José María Ricarte Bescós

REDMARKA UIMA-Universidad de A Coruña - CIECID 
6. La Fundación Biodiversidad del Ministerio de Medio Ambiente e Iberdrola Renovables han presentado el documental "Tierra. La película de nuestro planeta", producida por la BBC.

7. ROS, V. ebranding. Posiciona tu marca en la red. Editorial Netbiblo. A Coruña. 2008, Páginas 117 a 125.

\section{Bibliografía}

Alet, J. (2007): Marketing directo e interactivo, Barcelona: ESIC.

Alloza, A. (2001): "Gestión estratégica de la marca" en Informe Anual de la Publicidad y el Corporate en España y Latinoamérica, Madrid: Pirámide.

Bassat, L. (2008): Conferencia de Luis Bassat en "Los Desayunos IAB Spain", Madrid.

Berners-Lee, T. (2000): Tejiendo la red, Siglo XXI de España. Madrid.

Chaffey, D.; Mayer, R.; Johnston, K.; Ellis-Chadwich, F. (2003): "Internet

Marketing. Strategy, Implementation and Practice", Harlow: Prentice Hall.

Csikszentmihalyi, M. (1998): Creatividad. El fluir y la psicología del

descubrimiento y la invención, Barcelona: Paidós.

De Salas. M.I. La Comunicación empresarial a través de Internet. Editorial CEU Cardenal herrera. Valencia 2002

EIAA sobre la Eficacia del Branding Online http://www.eiaa.net/research/adeffectiveness.asp

Frazer, C. (1983): "Creative Strategy: a management perspective", en Journal of Advertising, vol. 12, n. 4.

Kotler, P., Lane, K. (2006): Dirección de marketing, Madrid: Pearson. 
Levine, R.; Locke, C.; Searls D.; y Weinberger, D. (2000): The Cluetrain Manifiesto, Perseus Book.

Moliné, M., (2005): "Reinwwwentando la publicidad" (on line). Artículo disponible en Internet en: http://www.moline-consulting.com/indexreinventando.htm.

Reeves, R. (1964): La realidad en la publicidad, Madrid: Severo-Ochoa.

Ros, V. "ebranding. Posiciona tu marca en la red". Editorial netbiblo. A Coruña 2008

Schmitt, B. H. (2000): Experiential Marketing, Bilbao: Deusto.

Tapscott, D. y Williams A.D. "Wikinomics. La nueva economía de las multitudes inteligentes". Paidós Empresa. Barcelona 2007.

Vallet Saavedra, G. (2005): "eBranding. La creación de marca digital en la era de la conectividad", Director de tesis: José $M^{a}$ Ricarte, Universidad Autónoma de Barcelona, Departamento de Comunicación Audiovisual y Publicidad.

Para citar este artículo:

Ros Diego, Vicente - De Salas Nestares, $M^{a}$ Isabel (12-02-2009). COMUNICACIÓN CORPORATIVA ON-LINE EN EL SECTOR MEDIOAMBIENTAL: SENSIBILIZACION Y PARTICIPACIÓN EN INTERNET.

REDMARKA - CIECID - Unidad de Investigación en Marketing Aplicado-Universidad de A Coruña, Número 2, V1, pp.3-35

ISSN 1852-2300

URL del Documento : http://www.cienciared.com.ar/ra/doc.php?n=1086

URL de la Revista : http://www.redmarka.org

REDMARKA UIMA-Universidad de A Coruña - CIECID 